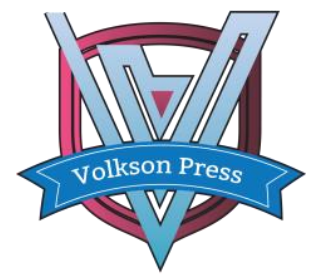

Contents List available at VOLKSON PRESS

Economics \& Management Innovations(EMI)

DOI : http://doi.org/10.26480/icemi.01.2017.208.210

\title{
Managing work of a special needs student.
}

\author{
Jan Tyburski, University of Warmia and Mazury in Olsztyn, Poland \\ Department of Foreign Languages \\ email: jantyburski@wp.pl \\ This is an open access article distributed under the Creative Commons Attribution License, which permits unrestricted use, distribution, and reproduction in any \\ medium, provided the original work is properly cited.
}

\section{ARTICLE DETAILS}

\section{Article History:}

Received 02 october 2017 Accepted 06 october 2017 Available online 11 october 2017

\section{Keywords:}

work management, dysfunction, special needs students, methods of activation, labour market.

\section{ABSTRACT}

The process of learning is undoubtedly a kind of work, since it has the same constituents and the same goals to be reached. A teacher is an equivalent of a CEO in business enterprises, and students may be viewed as employees. It is the teacher who sets goals and controls the process of acquiring knowledge. They are the students who do the work, who do the tasks, supervised by the teacher, who not only determines the objectives but also supports and helps if need be. The same holds true for regular enterprises, where a good manager controls and assists the process of work.Most articles present the teaching / learning process in the terms of methodology, different theories, sometimes put to practise, sometimes even not, but often the issue of managing work of a student is omitted. And a good planning is a vital part of progress. Everything should be thought over, well-prepared, and not left to chance. Because the student's work is the same work as any labourer, and nothing should be spoiled in obtaining the maximal effect. The aim of this paper is to show how manage the work of special needs students, how their physical restrictions can be overcome and how to make their work fruitful and successful. Providing a sense of success to a "regular" student is often a challenge, but giving the same feeling of achievement to a special needs student is especially difficult. It is a duty of the teacher to evoke trust in their students, to build up relations which foster cooperation, mutual understanding and make the student to work harder and more effectively not only for his/her own success, but also for the didactic success of their teacher. The issue of good relations is crucial. Only when the two a student and a teacher make a team, the work will almost certainly end up in a splendid achievement.

\section{Introduction}

Recently the issue of integration of people with different kind of impairments has become very popular not only in the mass media, but what is more important, in socio-economic reality of many countries. Thus, there are kindergartens which admit children with impairments to integrate them with fully healthy children, in order not to separate them, but just the contrary, to give them a feeling that they are fully accepted and form one society. The education continues up to universities. And here again the policy of higher schools is to provide such students with possibly the same opportunities as any other students. An impairment should be viewed as a challenge, something which can be overcome, if appropriate methods and tools are applied. And higher schools are the place where the future working staff for responsible posts is prepared. The better education they get, the easier their start will be as professional labourers. The problem of an appropriate preparation of impaired students for an adult life can be viewed from different points of view. It is not only a moral issue of giving these people a chance for a meaningful life, but also an important socio-economic issue. When employed they do not apply for social support but they can earn their living for themselves. Hence taking a part in such a project is fulfilling a dual role of a constructive organisation of their time and a preparation for their future successful work.

\section{Professional background}

The author has been a language teacher for over 25 years now. As an ardent believer in a pragmatic approach to life, he prefers practical solutions. He worked in a printing house for ten years, when he met with the problem of impairment workers for the first time. Some of his coworkers were namely deaf-mute. Working on regular terms with them he got to know their characteristic features, he learned how an impairment shapes life of an affected person. This experience has been continued in his teaching career, where he fully consciously chooses to work with special needs students. He hopefully gives them a feeling of success, and they repay his efforts in the joy he finds in working with them. The bigger challenge, the greater satisfaction he gets.

\section{Regular classes - case studies}

The author adopted in his work an approach based on the PCM (Project Cycle Management) prepared by the European Commission. After some modifications the process of teaching also consists of five stages and is shown in Fig. 1.

Fig. 1. The teaching / learning cycle as adopted by the author.

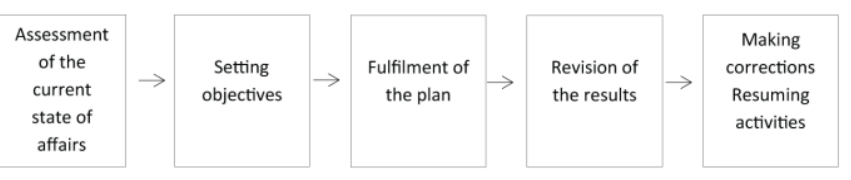

Source: by the author

The first stage, i.e. assessment of the state of affairs, consists of the following main elements:

- $\quad$ learning about the level of skills and knowledge (a placement test can be applied),

- $\quad$ getting to know the kind and intensity of an impairment,

- determination of the best methods of motivating the student.

The main elements of the second stage, i.e. setting objectives, are as follows:

- making a proposal of goals to be achieved,

- a joint discussion whether the goals are realistic and relevant,

- conclusion.

The third stage takes up the most time and means simply hard work for the two parties, the student(s) and the teacher. It can be divided into two sub-stages and namely:

- implementation of the agreed methods,

- a continuous supervision of the achieved results. 
analyses are made in this stage. It is composed of two sub-stages:

- gathering data on the goals which have been reached and these, whose achievement should be postponed,

- $\quad$ analysing the reasons of a didactic success and sometimes of a failure (what has gone right and what has gone wrong).

The fifth stage is the time of making decisions. It consists of the following elements:

- deciding what corrections should be made,

- implementation of these decisions in the future work.

The special need students taught by the author can be categorised into four main groups: blind and amblyopia students, these with a hearing impairment, partially paralysed ones, and those with psychological problems. Each of these groups require a different approach, and various methods especially tailored to the needs of an individual should be applied. The intensity of an impairment determines what kind of materials, what aids and methods are applicable, and decides how many and how long breaks should be made in order to ensure an appropriate concentration span [4]

In the case of an amblyopia student an enlarged print was applied first. It proved though that reading was too difficult, because the eyes got tired very quickly (after ca. 5 minutes), so the method was abandoned altogether. The good knowledge of spoken English allowed to shift the teaching method more to speaking and listening skills. The teacher adopted a method of reading exercises for the student three times. The first time the exercise was presented with detailed hints what should be done. The second time the text of the exercise was read but without the directions any remarks. The third time the content of the exercise was read line by line slowly allowing enough time for response. The same method is also recommended in $[1,5]$.

In the case of partially paralysed students writing activities are excluded. The voice is not clear, so the teacher should listen attentively to understand the student. The concentration span is usually short, up to 20 minutes. A 5-10 minute break should follow. Again listening and speaking activities are well-suited but also unaided reading this time. Similarly to blind and amblyopia people, the use of $\mathrm{CD}$ recording is possible and fully applicable. What is lost in one place (writing activities) should be regained by other skills $[2,3]$.

The hearing impairment requires yet a different approach and different measures ought to be taken. Speaking difficulties often accompany a full or partial deafness. This fact impels the usage of reading and writing. The way of communication is limited to writing, a sign language and facial expressions. Unfortunately, deaf-mute people are often impulsive and easily lose temper. This calls for special patience on the part of other students and the teacher as well [2].

\section{Methods}

As methods of research descriptive statistics and a survey were applied. To make sure that the results were true, a detailed interview with three volunteers was made. The review additionally completed these indicators which were not covered in the questionnaire. In total 20 people (both in groups dedicated for special needs students and in regular groups) were asked to answer shortly precise questions on the teacher himself and on the methods he used. The two parts of the questionnaire were clearly divided to facilitate the process of giving answers. The point was that the students should concentrate on the content of a given question, and not on the interpretation what the author might mean. The students were given enough time to answer all the questions. In case of a doubt, the students were encourage to ask additional questions for clarification. What seems important is the fact that the survey was done in their mother tongue, not in the target language, i.e. English. The aim was the same to receive trustworthy data, devoid of any errors of misinterpretation.

The review was conducted after completing the written survey within a week, so the volunteer students had freshly in mind the questions. (The printed form of the questionnaire was also provided.) As the aim of the additional review was to obtain more data on the way the teacher managed the classes, the students were asked to comment on the questionnaire point by point, and what was of a special importance, to add areas which were possibly omitted. The students were interviewed individually, one by one, not as a group, which allowed to express freely their concerns without being suggested by the statements of others. Each interview lasted ca. one hour, giving sufficient time to express their views.

\section{Results}

The results of the questionnaire proved that both the approach to the students' needs and the methods that were applied served well the cause. The initial goal of helping people in order to make the most of the time they had, allowed to manage the activities in a useful and meaningful way. And here is the questionnaire that was applied. The wording of the questions was as follows: (see Table 1.) The students were to evaluate the importance of a given factor in the scale of one (rather not) to five (very much so).

Table 1. A questionnaire on the course and its evaluation:

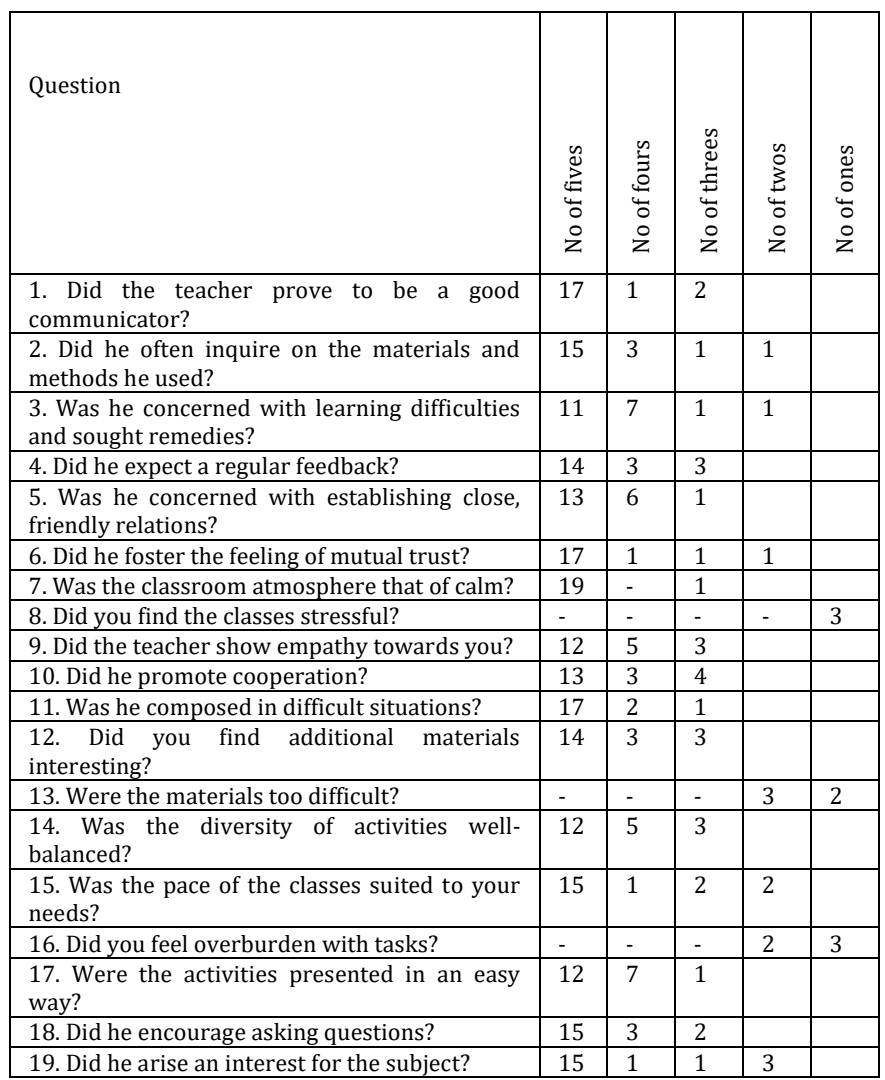

\section{Source: by the author}

As the results show the teacher proved to be successful in a number of the covered areas. The students appreciated very much communication skills. The teacher scored highly in question 6 , as being trustworthy. In question 7 , asking for a quiet way of conducting classes, the teacher proved to be very good indeed. The presentation of the material (question 11) proved again to be a strong point of the teacher. As the results show, unfortunately he paid too little attention for spotting problem areas and in solving these problems. Undoubtedly this area requires an urgent improvement.

The additional interview brought some new points which were not included in the survey. It proves that special needs people struggle with a strong stress, which they try very hard to hide. Thus some situations, some their reactions may seem not natural, almost artificial. It is true, according to the interviewees, that disabled people are more ambitious, that they try to recompense their disability with an additional effort. They also agree that the initiative for cooperation must come from the impaired student, they are to express first their expectations.

\section{Conclusion}

Disabled students, similarly to disabled workers, require special conditions in order to fully develop their skills and become very productive. As numerous experiences have showed workers with dysfunctions are as a rule more reliable than "regular" people. On the principle of compensation, they replace the restrictions they have with harder work and determination which enable them to achieve the same work results and often even better than their physically fit colleagues. The stronger the restriction is, the more powerful is the will to keep up with others. The strenuous efforts to adjust the working conditions to an individual case are justified by the results of these expenditures. The crucial factor lies in setting realistic, though at the same time ambitious goals, and in presenting the ways to reach them. The quality of this 
introductory stage is decisive, and mistakes which are made at the beginning prolong the process of learning and enhance its complexity.

A school was conceived as an introductory stage, a kind of preparation for meaningful adult life. The more and the better skills are acquired in a young age, the easier will be a successful professional career. In the case of the special needs students, it is a duty of the society to prepare them for a happy, fruitful life, where such people will be assets for the society, and not a burden. Their perception of the world enrich our views, their outlook may change the current state of affairs for the better.

\section{References}

[1] H. Rzepka, Blind and amblyopia students - a companion for higher schools, Kraków (2007) Fundacja Instytut Rozwoju Regionalnego
[2] D. M. Piekut-Brodzka and J. Kuczyńska-Kwapisz (editors), Special pedagogics Warszawa (2004) Akademia Pedagogiki Specjalnej im. Marii Grzegorzewskiej

[3] M. Czerwińska, Specificity of functioning and rehabilitation of disabled people, Zielona Gora University, Zielona Gora (2011)

[4] A. Rakowska, Language, communication, disability, UAM, Poznan (2010)

[5] S. Jakubowski (editor), A blind and amblyopia student in a regular secondary school, Warsaw (2005).

[6] J. Harmer, The Practice of English Language Teaching, Longman, Cambridge (2015). 